\title{
1 OVEREXPRESSION OF MIG-6 IN LIMB MESENCHYME LEADS TO \\ 2 ACCELERATED OSTEOARTHRITIS IN MICE
}

3

4

5 Bellini, Melina Rodrigues ${ }^{1,2}$, Pest, Michael Andrew ${ }^{1,2}$, Jae-Wook Jeong ${ }^{4}$, Beier, Frank ${ }^{1,2,3}$

6

$7 \quad{ }^{1}$ Department of Physiology and Pharmacology, Western University, London, ON, Canada

$8 \quad{ }^{2}$ Western University Bone and Joint Institute, London, ON, Canada

$9 \quad{ }^{3}$ Children's Health Research Institute, London, ON, Canada

$10{ }^{4}$ Department of Obstetrics, Gynecology and Reproductive Biology, Michigan State University

11 College of Human Medicine, Grand Rapids, Michigan.

12

13 Corresponding author: Dr. Frank Beier, Department of Physiology and Pharmacology,

14 Western University, London, ON, Canada; Phone 519-661-2111 ext 85344; email:

15 fbeier@uwo.ca

16

17 The authors have no conflicts of interest to declare. 


\section{ABSTRACT}

37 Background: Mitogen-inducible gene 6 (Mig-6) is a tumour suppressor gene that is also 38 associated with the development of osteoarthritis (OA)-like disorder. Recent evidence from our 39 lab and others showed that cartilage-specific Mig-6 knockout (KO) mice develop chondro40 osseous nodules, along with increased articular cartilage thickness and enhanced EGFR signaling 41 in the articular cartilage. Here, we evaluate the phenotype of mice with skeletal-specific 42 overexpression of Mig-6.

44 Methods: Synovial joint tissues of the knee were assessed in 12 and 36 weeks-old skeleton45 specific Mig-6 overexpressing (Mig-6 $6^{\text {over/over }}$ ) and control animals using histological stains, 46 immunohistochemistry, semi-quantitative OARSI scoring, and microCT for skeletal 47 morphometry. Measurement of articular cartilage and subchondral bone thickness were also 48 performed using histomorphometry.

Results: Our results show only subtle developmental effects of Mig-6 overexpression. However,

51 male Mig- $6^{\text {over/over }}$ mice show accelerated cartilage degeneration at 36 weeks of age, in both 52 medial and lateral compartments of the knee. Immunohistochemistry for SOX9 and PRG4 53 showed decreased staining in Mig- $6^{\text {over/over }}$ mice relative to controls, providing potential 54 molecular mechanisms for the observed effects.

55 Conclusion: Overexpression of Mig-6 in articular cartilage causes no major developmental 56 phenotype but results in accelerated development of OA during aging. These data demonstrate 57 that precise regulation of the Mig-6/EGFR pathway is critical for joint homeostasis. 


\section{INTRODUCTION}

Osteoarthritis (OA) is a failure of joint homeostasis and results in the whole-joint tissue degeneration (1). In fact, $\mathrm{OA}$ is a multifactorial disease affecting 630 million individuals worldwide, and the economic impact of OA treatment is estimated at 190 billion dollars in direct and indirect health care costs in North America annually (2,3). OA patients experience limits in daily activities and often suffer from co-morbidities including mental health disorders (4). Treatment for pain and inflammation (analgesics, non-steroidal anti-inflammatory drugs (NSAIDS) and targeted physiotherapy (5) are commonly used to address patients' symptoms, but no effective pharmacological therapy is currently available to delay disease progression. Future directions for effective OA management rely on better understanding of joint physiology and pathophysiological mechanism to develop disease-modifying therapies for OA patients.

Risk factors including aging, genetics, obesity, and trauma contribute to the dysfunction

74 of joint structures in OA. During the early stages of OA, alteration in chondrocyte physiology

75 including cluster formation and changes in the composition of extracellular matrix (ECM) lead to

76 altered cartilage function (6-8). Gradual degeneration of the articular cartilage, subchondral bone sclerosis, osteophyte development, and synovial inflammation/hyperplasia all contribute to joint degeneration in OA (9-11). Expression of matrix metalloproteinases (MMPs) (i.e., MMP-1 and MMP-13) and aggrecanases (disintegrin and metalloproteinase with a thrombospondin type 1 motif (ADAMTS) (i.e., ADAMTS 1,4,5) is up-regulated in response to inflammatory factors and other signals (12-14). Importantly, the tissues of the whole joint work together to maintain joint homeostasis. Therefore, failure in one joint structure might lead to failure of the whole organ, such as the knee joint (15).

Over the past two decades, epidermal growth factor receptor (EGFR) signaling has been studied in several stages of cartilage development and homeostasis. These studies demonstrate

86 both degenerative and protective roles of this pathway (16), with potential therapeutic

87 implications for OA (17-26). EGFR signaling modulates many canonical signaling pathways

88 including MEK/ERK that have been implicated in cellular proliferation and growth in cartilage 89 and bone, as well as Jun N-terminal kinases (JNKs), PLC-PKC signaling and others $(24,27,28)$.

90 Mitogen inducible gene 6 (Mig-6) is well-known as a negative regulator for EGFR signaling 91 (29). Two different mouse strains with global deletion of Mig-6 demonstrated bone erosion and 92 spontaneous development of OA-like phenotypes (30,31). Cartilage-specific Mig-6 KO mice 93 display normal early bone development, but show anabolic buildup of articular cartilage, and 
94 formation of chondro-osseous nodules at 12 and 36 weeks of age (32). Another study using limb

95 mesenchyme-specific deletion of Mig-6 in mice (using the Prxl-cre driver line) demonstrated

96 similar phenotypes as those observed in cartilage-specific knockout mice (33). Our laboratory

97 has shown that cartilage-specific Mig-6 overexpression in mice results in no major

98 developmental abnormalities in articular cartilage, however, during aging (12 and 18 months)

99 Mig-6 ${ }^{\text {over/over }}$ mice show accelerated cartilage degeneration (34). To evaluate the contribution of

100 Mig-6 in multiple joint tissues to joint homeostasis and OA pathogenesis, we used Prx1

101 promoter-driven Cre recombinase to selectively overexpress Mig-6 in all mesenchymal limb

102 tissues in mice.

103

104 Materials and Methods

105 Animals

106 All animals and procedures were approved by the Council for Animal Care (CCAC) at Western 107 University-Canada (Animal use permit:2015-031). Mig-6 overexpression animals with the 108 overexpression targeted to the Rosa26 locus (35) were backcrossed for 10 generations into a $109 \mathrm{C} 57 \mathrm{~B} 1 / 6$ background. In these mice, transcription of Mig-6 is under the control of a ubiquitously 110 expressed chicken beta actin-cytomegalovirus hybrid (CAGGS) promoter, but blocked by a 111 "Stop Cassette" flanked by LoxP sites (LSL) (35). Mig-6 overexpression mice were bred to mice 112 carrying the Cre recombinase gene under the control of the Prx1-Cre transgene (36) to induce 113 recombination and removal of the Stop Cassette specifically in early limb bud mesenchyme. 114 Animals with overexpression of Mig-6 from both alleles are termed Mig-6 ${ }^{\text {over/over }}$ (Mig-6

$115{ }^{\text {over/over }} \operatorname{Prxl}-\mathrm{Cr}^{+/}$), while control mice are identical but without the Cre gene (denoted "control" 116 for simplicity). Mice were group housed ( 2 or 4 mice per cage of littermate matched control and 117 overexpression animals), on a standard 12 hour light/dark cycle, and with free access to mouse 118 chow and water. Genotyping and assessment of genomic recombination was performed on DNA 119 samples from ear tissue from mice surviving to at least 21 days of age. Standard polymerase 120 chain reaction (PCR) was performed using primer set P1 and P2 can amplify a 300 bp fragment 121 from the wild-type allele, whereas P1 and P3 can amplify a $450 \mathrm{bp}$ fragment from the targeted 122 ROSA26 locus allele (35).

\section{Histologic Assessment}

125 The knee joints of mice were dissected and fixed in $4 \%$ paraformaldehyde in phosphate 
126 buffered saline (PBS, $\mathrm{pH}$ 7.0) for 24 hours at room temperature. The intact joints were then 127 decalcified in 5\% ethylenediaminetetraacetic acid (EDTA) in phosphate buffered saline (PBS), $128 \mathrm{pH} 7.0$ for $10-12$ days at room temperature. All joints were processed and embedded in paraffin 129 in sagittal or frontal orientation, with serial sections taken at a thickness of $5 \mu \mathrm{m}$. Sections were 130 stained with Toluidine Blue $(0.04 \%$ toluidine blue in $0.2 \mathrm{M}$ acetate buffer, $\mathrm{pH} 4.0$, for 10 131 minutes) for glycosaminoglycan content and general evaluation of articular cartilage. 132 Immunohistochemistry was performed on frontal sections of paraffin embedded knee 133 joints as previously described (32,37). Primary antibodies against SOX9 (R\&D Systems, 134 AF3075), MMP13 (Protein Tech, Chicago, IL, USA, 18165-1-AP), and lubricin (Abcam, $135 \mathrm{ab} 28484)$ were used and slides without primary antibody were used as control. Sections were 136 incubated with primary antibody overnight at $4^{\circ} \mathrm{C}$. After washing, sections were incubated with 137 horseradish peroxidase (HRP)-conjugated donkey anti-goat or goat anti-rabbit secondary 138 antibody (R\&D system and Santa Cruz), before incubation with diaminobenzidine substrate as a 139 chromogen (Dako, Canada). Finally, sections were counterstained with $0.5 \%$ methyl green 140 (Sigma) and dehydrated in graded series of 70-100\% ethanol in water, followed by $100 \%$ xylene, 141 and mounted using xylene-based mounting media. All images were taken using a Leica DM1000 142 microscope with attached Leica DFC295 digital camera.

\section{Histologic evaluation of articular cartilage and histopathology scoring}

144 Articular cartilage thickness was determined from toluidine blue-stained frontal sections 145 of knee joints by a blinded observer with regard to the tissue source. ImageJ Software (v.1.51) 146 (38) was used to measure the cartilage thickness separately for the non-calcified articular 147 cartilage (measured from the superficial tangential zone to the tidemark) and the calcified 148 articular cartilage (measured from the subchondral bone to the tidemark) across three evenly 149 spaced points from all four quadrants of the joint (medial/lateral tibia and femur), in 4 sections 150 spanning at least $500 \mu \mathrm{m}$. For OARSI scoring, Toluidine blue-stained sections were evaluated by 151 one to two blinded observers (MB, MAP) on the four quadrants of the knee: lateral femoral 152 condyle (LFC), lateral tibial plateau (LTP), medial femoral condyle (MFC), and medial tibial 153 plateau (MTP), according to the Osteoarthritis Research Society International (OARSI)

154 histopathologic scale (39). Subchondral bone area from the tibial plateau was traced by one 155 observer (MB) using the Osteomeasure analysis software (OsteoMetrics, Decatur, GA, USA) for 156 histomorphometry measurements using three sections spanning at least $500 \mu \mathrm{m}$ from each 
157 animal.

159 Visualization of collagen fiber content

In order to analyze the collagen fibril content and network, Picrosirius Red Staining $161(0.1 \%$ Sirius red in saturated picric acid solution for 60 minutes, with $0.5 \%$ acetic acid washes) 162 was performed (32). Stains were imaged under polarized light microscopy to visualize the 163 organization and size of collagen fibrils. Light intensity and tissue angle $\left(45^{\circ}\right)$ relative to 164 polarizing filter (Leica no. 11505087) and analyzer (Leica no. 11555045) were kept identical 165 between samples as per (32).

\section{Micro-Computerized Tomography $(\boldsymbol{\mu C T})$}

167 Mice were euthanized and imaged using General Electric (GE) SpeCZT microCT 168 machine (40) at a resolution of $50 \mu \mathrm{m} / \mathrm{voxel}$ or $100 \mu \mathrm{m} / \mathrm{voxel}$ in 12 and 36 week-old control and 169 Mig-6 ${ }^{\text {over/over }}$ male and female mice. GE Healthcare MicroView software (v2.2) was used to 170 generate 2D maximum intensity projection and 3D isosurface images to evaluate skeletal 171 morphology $(32,41)$. MicroView was used to create a line measurement tool in order to calculate 172 the bone lengths; femurs lengths were calculated from the proximal point of the greater 173 trochanter to the base of the lateral femoral condyle. Tibiae lengths were measured from the 174 midpoint medial plateau to the medial malleolus. Humerus lengths were measured from the 175 midpoint of the greater tubercle to the center of the olecranon fossa.

\section{Statistical Analysis}

178 All statistical analyses were performed using GraphPad Prism (v6.0). Differences 179 between two groups were evaluated using Student's $t$-test, and Two-Way ANOVA was used to 180 compare 4 groups followed by a Bonferroni multiple comparisons test. All $n$ values represent the 181 number of mice used in each group/genotyping. 


\section{RESULTS}

Overexpression of Mig-6 has minor effects on body weight during development

Mice with alleles for conditional overexpression of Mig-6 (35) were bred to mice expressing Cre recombinase under control of the Prx1 promoter, which is active in the mesenchyme of developing limb buds. Homozygote mice overexpressing Mig-6 in mesenchymal limb tissue from both Rosa26 alleles are referred to as Mig-6 ${ }^{\text {over/over }}$ from here on. Control mice do not express Cre recombinase. Overexpressing mice were obtained at the expected Mendelian ratios (data not shown). Animal weights were significantly lower at 7, 12, and 13 weeks after birth in male mutant mice compared to control mice (Fig. 1A), while female Mig- $6^{\text {over/over }}$ mice had similar weights as control mice (Fig. 1B). However, at 36 weeks of age mice there were no

193 differences in weights of either male nor female mutant mice compared to the control group (Fig.

$1941 \mathrm{C}, \mathrm{D})$.

\section{Mig-6 overexpressing mice show no differences in bone length}

Micro computed tomography (microCT) was used to investigate skeletal morphology and bone length. Whole body microCT scans of Mig-6 ${ }^{\text {over/over }}$ male mice and their controls were taken post-mortem at 12 and 36 weeks of age to generate 3D isosurface reconstructions of $50 \mu \mathrm{m} /$ voxel uCT scans, in order to measure long bones lengths (femurs, humeri, and tibiae) in GE MicroView v2.2 software. Mutant male mice at 12 and 36 weeks did not show any difference in bone length compared to controls (Fig. 2A-B). Moreover, no differences in gross skeletal

\section{Specific overexpression of Mig-6 in limbs display healthy articular cartilage at skeletal} maturity morphology were detected (Fig. 2C).

Histologically analysis of knee sections was performed on 12 week-old mutant and

211 (MTP) of male Mig-6 ${ }^{\text {over/over }}$ mice was statistically significant lower than in controls. Uncalcified 212 cartilage did not show any differences between genotypes. 
We evaluated the knee joints of 36 weeks-old control and Mig-6 ${ }^{\text {over/over }}$ male mice using

216 toluidine blue staining and OARSI grading method (39). At this age, control mice exhibited little

217 to no damage of articular cartilage (Fig. 4A). Conversely, three of seven Mig- ${ }^{\text {over/over }}$ mice

218 exhibited cartilage damage and erosion with significantly elevated scores in the medial

219 compartment of the knee. Moreover, all seven Mig-6 ${ }^{\text {over/over }}$ mice had OA in the lateral

220 compartment of the knee (Fig. 4B), with fibrillation and fissure formation. Furthermore, two of

221 six Mig-6 ${ }^{\text {over/over }}$ female mice showed mild cartilage degeneration of the medial compartment

222 (Fig. 5B), in contrast to the control group where no cartilage damage was observed (Fig. 5A).

\section{Specific overexpression of Mig-6 results in normal bone area}

224 Bone structural alteration is related to knee osteoarthritis as an adaptive response to the 225 loading distribution across joints (42). Measurement of the subchondral bone area from Mig-6 over/over and controls male mice at 36 weeks-old across the entire joint did not reveal any significant differences between genotypes (Fig. 6A-B). Specific measurements of the lateral and medial tibia plateau did not show any significant differences either (data not shown).

\section{Mig-6 overexpressing mice display altered collagen fiber organization in articular cartilage}

Frontal sections from 36 weeks-old male mice were stained with Picrosirius red to visualize the collagen network under polarized light microscope. In the control male mice, the

232 collagen fibers in the articular cartilage exhibit greenish/yellow birefringence in the superficial 233 and transitional zones, resulting from thin collagen fibers in these regions. In the deep and 234 calcified cartilage, and in bone, red birefringent fibers are visualized, indicating larger fiber 235 diameter in these regions. The articular cartilage of Mig-6 ${ }^{\text {over/over }}$ showed fewer green collagen 236 fibers in the medial compartment of the knee, indicating a loss of normal collagen fibers (Fig. 237 7A-B).

238 Overexpression of Mig-6 decreases Sox9 expression

239 Studies have shown that expression of the transcription factor SRY (sex determining 240 region Y)-box 9 [SOX9] was increased in articular cartilage upon both Prx1-Cre 1(43) and Col2241 Cre-driven deletion of Mig-6 (32). SOX9 is an essential regulator of chondrogenesis and the 242 maintenance of a chondrocyte-like phenotype (44). Frontal sections of paraffin embedded knees 243 from 12 and 36 week-old male mice were used for SOX9 immunostaining. In 12 weeks-old 
244 control mice, nuclear SOX9 was abundantly present in the articular cartilage of the knee joints in

245 all four quadrants. In contrast, Mig- $6^{\text {over/over }}$ mice appear to have fewer cells staining positive in 246 both lateral and medial compartments (Fig. 8A,B). 36 week-old Mig-6 ${ }^{\text {over/over }}$ mice showed a

247 further reduction in SOX9 immunostaining in the lateral quadrant, while the loss of cartilage in 248 the medial compartment led to an absence of SOX9 staining (Fig. 9A,B). For both ages, 249 negative controls did not show staining in chondrocytes (data not shown).

\section{Lubricin/PGR4 is slightly decreased upon Mig-6 overexpression}

Lubricin/proteoglycan 4 plays an important role as joint boundary lubricant and is 253 produced by synoviocytes as well as superficial zone chondrocytes $(45,46)$. In 12 week-old Mig$2546^{\text {over/over }}$ mice, lubricin was observed in superficial zone (SZ) and middle zone (MZ) 255 chondrocytes, in a similar pattern as control mice, although intensity appeared reduced in 256 overexpressors (Fig. 10 A-C). 36 weeks-old control male mice show lubricin immunostaining in 257 the SZ and MZ, however, less lubricin immunostaining is present in the SZ of the medial side of 258 Mig-6 ${ }^{\text {over/over }}$ mice. Negative controls did not show staining in chondrocytes or articular cartilage 259 at either age (Fig. 11 A-C).

MMP13 immunostaining is increased in Mig-6-overexpressing compared to control mice

Previous studies have shown that matrix metalloproteinase (MMP) 13 is the main collagenase associated with type II collagen destruction in OA. Frontal sections of knees from 36 week-old control and Mig- $6^{\text {over/over }}$ male mice were used for MMP13 immunohistochemistry.

265 While some staining was seen in control mice, intensity of staining was increased in areas of

266 damage on the medial side of Mig-6 ${ }^{\text {over/over }}$ mice. Negative controls did not show staining in 267 cartilage or subchondral bone (Fig. 12 A,B and C). 


\section{Discussion}

Mig-6 has been studied in a variety of human diseases, including cancer and more 280 recently OA progression(16,31-33,47). Many studies, including from our lab, also identified $281 \mathrm{TGF} \alpha /$ EGFR signaling as a regulator of OA progression and cartilage homeostasis $(21,24,48)$. 282 Interestingly, cartilage-specific (Col2-Cre) deletion of Mig-6 (Mig-6 KO) (32) results in 283 increased proliferation of chondrocytes and a thicker layer of cartilage while skeletal-specific 284 (Prx1-Cre) deletion of Mig-6 results in transient anabolic buildup of cartilage followed by 285 catabolic events such as cartilage degeneration at 16 weeks of age (33). In fact, global deletion of 286 Mig-6 in mice results in a complex set of phenotypes, including joint damage at relatively early 287 time-points in a surgical mouse model $(31,49,50)$. Previous research demonstrates that Mig-6 288 acts as a negative feedback inhibitor of EGFR signaling (51). Thus, Mig-6 has been suggested as 289 a potential tumor suppressor, as a suppressor of EGFR signaling in human carcinomas $(35,52-$ 290 55). Recent work has revealed that overexpression of Mig-6 acts as a negative regulator of 291 EGFR-ERK signalling in mouse uterus (35). In our study, we set out to evaluate the role of Mig2926 in joint physiology by using skeletal-specific constitutive overexpression of Mig-6. In this 293 study, we show no major effects of Mig-6 overexpression on bone length at the ages of 12 or 36 294 weeks. While male Mig-6 $6^{\text {over/over }}$ mice did show slightly reduced body weight up to 12 weeks 295 after birth, these differences were no longer present at 36 weeks of age.

Our results show that Mig- $6^{\text {over/over }}$ (Prx1-Cre) male mice developed cartilage lesions at 36 weeks of age, where control mice show healthy cartilage. OARSI scores of Mig- $6^{\text {over/over }}$ mice 298 reveal significantly increased cartilage degeneration compared to control group. Surprisingly, it 299 appeared that cartilage degeneration in Mig- $6^{\text {over/over }}$ mice was not accompanied by any obvious 300 changes in subchondral bone. However, the thickness of the calcified articular cartilage in Mig$3016^{\text {over/over }}$ was significantly decreased at the 12-week time-point, at least in the medial 302 compartment. It is currently unclear whether and how this is related to the subsequent 303 degeneration of articular cartilage in these mice.

304 SOX9 is a transcription factor that is necessary for the formation of mesenchymal 305 condensations as well as chondrocyte differentiation and proliferation $(56,57)$. Our data suggest a 306 lower number of SOX9-positive cells at the 12-week time point in mutant mice, preceding 307 cartilage damage. The number of SOX9-expressing cells is further reduced in 36 week-old 
mutant mice, although this is partially due to the loss of cartilage and chondrocytes. In agreement with these data, mice with cartilage- or limb mesenchyme-specific deletion of Mig- 6 showed increased expression of SOX9 in the articular cartilage $(32,33)$.

$312(58,59)$.

313 Our results suggest a slight decrease in lubricin staining in 12 weeks-old male Mig-6 ${ }^{\text {over/over }}$

314 mice, compared to the control group. We also observed the same trend towards decreased

315 staining in 36 weeks-old male Mig-6 over/over mice. Together, these data suggest that the 316 decreased of SOX9 and lubricin in the articular cartilage could contribute to cartilage 317 degeneration in our mutant mice.

318 We recently described mice with cartilage-specific (Col2-Cre-driven) overexpression of 319 Mig-6 (34). Despite the differences in recombination patterns conferred by the two different Cre 320 drivers, overall the phenotypes observed upon Mig-6 overexpression are quite similar. Both are 321 characterized by no or only subtle developmental defects, followed by reduced SOX9 and 322 lubricin expression, followed by cartilage degeneration. One unique feature of the Prx1-driven 323 Mig6-overexpression described here is the stronger OA phenotype in the lateral compartment of 32436 week-old mutant male mice. Future studies will need to investigate the underlying causes.

325 While Mig-6 had been identified as a negative regulator of EGFR signaling, it also 326 interacts with a number of other potential candidate proteins that may contribute to the 327 phenotype described here, such as Cdc42 (60), c-Abl (61), and the hepatocyte growth factor 328 receptor c-Met (62). Therefore, additional work is necessary to elucidate the potential role of 329 these proteins in the phenotype presented. In conclusion, in this study using limb mesenchyme330 specific Mig-6 overexpression we show a reduction of SOX9 and PRG4 expression, and 331 accelerated cartilage damage. The data highlights the importance of more studies on the specific 332 role of Mig-6 signaling in joint homeostasis and OA development. 


\section{Acknowledgements}

341 We would like to thank Julia Bowering for performing joint sectioning. We thank all 342 members of the Beier lab for discussions and help. M.B. was supported by a fellowship from $343 \mathrm{CNPq} /$ Brazil. Work in the lab of F.B. is supported by a grant from the Canadian Institutes of 344 Health Research (Grant \#332438). F.B. holds the Canada Research Chair in Musculoskeletal 345 Research. 


\section{References}

374 1. Nuki, G. Osteoarthritis: a problem of joint failure. Z. Rheumatol. 58, 142-7 (1999).

375 2. Badley, E. M. The effect of osteoarthritis on disability and health care use in Canada. $J$.

$376 \quad$ Rheumatol. Suppl. 43, 19-22 (1995).

377 3. Kotlarz, H., Gunnarsson, C. L., Fang, H. \& Rizzo, J. A. Insurer and out-of-pocket costs of 378 osteoarthritis in the US: Evidence from national survey data. Arthritis Rheum. 60, 3546$3793553(2009)$.

380 4. Nazarinasab, M., Motamedfar, A. \& Moqadam, A. E. Investigating mental health in patients with osteoarthritis and its relationship with some clinical and demographic factors. Reumatologia 55, 183-188 (2017).

5. Berenbaum, F. New horizons and perspectives in the treatment of osteoarthritis. Arthritis Res. Ther. 10, S1 (2008).

6. Carballo, C. B., Nakagawa, Y., Sekiya, I. \& Rodeo, S. A. Basic Science of Articular Cartilage. Clin. Sports Med. 36, 413-425 (2017).

7. Nam, J. et al. Sequential Alterations in Catabolic and Anabolic Gene Expression Parallel Pathological Changes during Progression of Monoiodoacetate-Induced Arthritis. PLoS One 6, e24320 (2011).

8. Lorenzo, P., Bayliss, M. T. \& Heinegård, D. Altered patterns and synthesis of

393 9. Bush, J. R. \& Beier, F. TGF- $\beta$ and osteoarthritis - the good and the bad. Nat. Med. 19, 667-669 (2013).

395 10. Blaney Davidson, E. N. et al. Inducible chondrocyte-specific overexpression of BMP2 in young mice results in severe aggravation of osteophyte formation in experimental OA without altering cartilage damage. Ann. Rheum. Dis. 74, 1257-1264 (2015).

11. Goldring, M. B. et al. Cartilage homeostasis in health and rheumatic diseases. Arthritis Res. Ther. 11, 224 (2009).

12. Kaspiris, A. et al. Subchondral cyst development and MMP-1 expression during progression of osteoarthritis: An immunohistochemical study. Orthop. Traumatol. Surg. 
Res. 99, 523-529 (2013).

13. Liacini, A. et al. Induction of matrix metalloproteinase-13 gene expression by TNF-alpha is mediated by MAP kinases, AP-1, and NF-kappaB transcription factors in articular chondrocytes. Exp. Cell Res. 288, 208-17 (2003).

14. Song, R.-H. et al. Aggrecan degradation in human articular cartilage explants is mediated by both ADAMTS-4 and ADAMTS-5. Arthritis Rheum. 56, 575-585 (2007).

15. Kapoor, M., Martel-Pelletier, J., Lajeunesse, D., Pelletier, J.-P. \& Fahmi, H. Role of proinflammatory cytokines in the pathophysiology of osteoarthritis. Nat. Rev. Rheumatol. 7, 33-42 (2011).

16. Qin, L. \& Beier, F. EGFR Signaling: Friend or Foe for Cartilage? JBMR Plus 3, e10177 (2019).

17. Appleton, C. T. G., Pitelka, V., Henry, J. \& Beier, F. Global analyses of gene expression in early experimental osteoarthritis. Arthritis Rheum. 56, 1854-1868 (2007).

18. Appleton, C. T. G., Usmani, S. E., Bernier, S. M., Aigner, T. \& Beier, F. Transforming growth factor $\alpha$ suppression of articular chondrocyte phenotype andSox 9 expression in a rat model of osteoarthritis. Arthritis Rheum. 56, 3693-3705 (2007).

19. Usmani, S. E. et al. Transforming growth factor alpha controls the transition from hypertrophic cartilage to bone during endochondral bone growth. Bone 51, 131-141 (2012).

21. Usmani, S. E. et al. Context-specific protection of TGF $\alpha$ null mice from osteoarthritis. Sci. Rep. 6, 30434 (2016).

22. Cui, G. et al. Association of Common Variants in TGFA with Increased Risk of Knee doi:10.1089/gtmb.2017.0045

23. Zengini, E. et al. Genome-wide analyses using UK Biobank data provide insights into the genetic architecture of osteoarthritis. Nat. Genet. 20181 (2018). doi:10.1038/s41588-0180079-y 
25. Wang, K., Yamamoto, H., Chin, J. R., Werb, Z. \& Vu, T. H. Epidermal growth factor receptor-deficient mice have delayed primary endochondral ossification because of defective osteoclast recruitment. J. Biol. Chem. 279, 53848-56 (2004).

26. Jia, H. et al. EGFR signaling is critical for maintaining the superficial layer of articular cartilage and preventing osteoarthritis initiation. Proc. Natl. Acad. Sci. U. S. A. 201608938 (2016). doi:10.1073/pnas.1608938113

27. Schneider, M. R., Sibilia, M. \& Erben, R. G. The EGFR network in bone biology and pathology. Trends Endocrinol. Metab. 20, 517-524 (2009).

28. Mariani, E., Pulsatelli, L. \& Facchini, A. Signaling pathways in cartilage repair. Int. J. Mol. Sci. 15, 8667-98 (2014).

29. Frosi, Y. et al. A two-tiered mechanism of EGFR inhibition by RALT/MIG6 via kinase suppression and receptor degradation. J. Cell Biol. 189, 557-71 (2010).

30. Ferby, I. et al. Mig6 is a negative regulator of EGF receptor-mediated skin morphogenesis and tumor formation. Nat. Med. 12, 568-573 (2006).

31. Joiner, D. M. et al. Accelerated and increased joint damage in young mice with global

32. Pest, M. A., Russell, B. A., Zhang, Y.-W., Jeong, J.-W. \& Beier, F. Disturbed cartilage and joint homeostasis resulting from a loss of mitogen-inducible gene 6 in a mouse model of joint dysfunction. Arthritis Rheumatol. (Hoboken, N.J.) 66, 2816-27 (2014).

33. Shepard, J. B., Jeong, J.-W., Maihle, N. J., O’Brien, S. \& Dealy, C. N. Transient anabolic effects accompany epidermal growth factor receptor signal activation in articular cartilage in vivo. Arthritis Res. Ther. 15, R60 (2013).

34. Bellini, M., Pest, M. A., Miranda-Rodrigues, M., Jeong, J. \& Beier, F. Overexpression of

35. Kim, T. H. et al. Mig-6 suppresses endometrial cancer associated with pten deficiency and ERK activation. Cancer Res. 74, 7371-7382 (2014).

463 36. Logan, M. et al. Expression of Cre recombinase in the developing mouse limb bud driven by aPrxl enhancer. genesis 33, 77-80 (2002).

465 37. Ratneswaran, A. et al. Peroxisome proliferator-activated receptor $\delta$ promotes the 
progression of posttraumatic osteoarthritis in a mouse model. Arthritis Rheumatol. (Hoboken, N.J.) 67, 454-64 (2015).

38. Schneider, C. A., Rasband, W. S. \& Eliceiri, K. W. NIH Image to ImageJ: 25 years of image analysis. Nat. Methods 9, 671-675 (2012).

39. Glasson, S. S., Chambers, M. G., Van Den Berg, W. B. \& Little, C. B. The OARSI histopathology initiative - recommendations for histological assessments of osteoarthritis in the mouse. Osteoarthr. Cartil. 18, S17-S23 (2010).

40. Beaucage, K. L., Pollmann, S. I., Sims, S. M., Dixon, S. J. \& Holdsworth, D. W. Quantitative in vivo micro-computed tomography for assessment of age-dependent changes in murine whole-body composition. Bone Reports 5, 70-80 (2016).

41. Dupuis, H. et al. Exposure to the RXR agonist SR11237 in early life causes disturbed skeletal morphogenesis in a rat model. bioRxiv 774851 (2019). doi:10.1101/774851

42. Lowitz, T. et al. Characterization of knee osteoarthritis-related changes in trabecular bone using texture parameters at various levels of spatial resolution-a simulation study. Bonekey Rep. 3, 615 (2014).

43. Shepard, J. B., Jeong, J.-W., Maihle, N. J., O’Brien, S. \& Dealy, C. N. Transient anabolic effects accompany epidermal growth factor receptor signal activation in articular cartilage in vivo. Arthritis Res. Ther. 15, R60 (2013).

44. Akiyama, H., Chaboissier, M.-C., Martin, J. F., Schedl, A. \& de Crombrugghe, B. The transcription factor Sox9 has essential roles in successive steps of the chondrocyte differentiation pathway and is required for expression of Sox5 and Sox6. Genes Dev. 16, 2813-28 (2002).

45. Coles, J. M. et al. Loss of cartilage structure, stiffness, and frictional properties in mice lacking PRG4. Arthritis Rheum. 62, 1666-1674 (2010).

492 47. Zhang, Y.-W. \& Vande Woude, G. F. Mig-6, Signal Transduction, Stress Response and Cancer. Cell Cycle 6, 507-513 (2007).

494 48. Usmani, S. E., Appleton, C. T. G. \& Beier, F. Transforming growth factor-alpha induces endothelin receptor A expression in osteoarthritis. J. Orthop. Res. 30, 1391-7 (2012).

496 49. Zhang, Y.-W. et al. Targeted disruption of Mig-6 in the mouse genome leads to early 
50. Jin, N., Gilbert, J. L., Broaddus, R. R., Demayo, F. J. \& Jeong, J.-W. Generation of a Mig6 conditional null allele. Genesis 45, 716-21 (2007).

500 51. Hackel, P. O., Gishizky, M. \& Ullrich, A. Mig-6 Is a Negative Regulator of the Epidermal Growth Factor Receptor Signal. Biol. Chem. 382, (2001).

52. Maity, T. K. et al. Loss of MIG6 Accelerates Initiation and Progression of Mutant Epidermal Growth Factor Receptor-Driven Lung Adenocarcinoma. Cancer Discov. 5, 534-49 (2015).

53. Li, Z. et al. Downregulation of Mig-6 in nonsmall-cell lung cancer is associated with EGFR signaling. Mol. Carcinog. 51, 522-34 (2012).

54. Zhang, Y.-W. et al. Evidence that MIG-6 is a tumor-suppressor gene. Oncogene 26, 269276 (2007).

55. Sasaki, M., Terabayashi, T., Weiss, S. M. \& Ferby, I. The Tumor Suppressor MIG6 Controls Mitotic Progression and the G2/M DNA Damage Checkpoint by Stabilizing the WEE1 Kinase. Cell Rep. 24, 1278-1289 (2018).

56. Kobayashi, T. \& Kronenberg, H. Minireview: Transcriptional Regulation in Development of Bone. Endocrinology 146, 1012-1017 (2005).

57. Akiyama, H. The transcription factor Sox 9 has essential roles in successive steps of the chondrocyte differentiation pathway and is required for expression of Sox5 and Sox6. Genes Dev. 16, 2813-2828 (2002).

59. Ruan, M. Z. C. et al. Proteoglycan 4 Expression Protects Against the Development of

58. Flannery, C. R. et al. Prevention of cartilage degeneration in a rat model of osteoarthritis Osteoarthritis. Sci. Transl. Med. 5, 176ra34-176ra34 (2013).

60. Jiang, X. et al. Inhibition of Cdc42 is essential for Mig-6 suppression of cell migration

524 61. Hopkins, S. et al. Mig6 is a sensor of EGF receptor inactivation that directly activates cAbl to induce apoptosis during epithelial homeostasis. Dev. Cell 23, 547-59 (2012). 
bioRxiv preprint doi: https://doi.org/10.1101/871350; this version posted December 10,2019 . The copyright holder for this preprint (which was not certified by peer review) is the author/funder, who has granted bioRxiv a license to display the preprint in perpetuity. It is made available under aCC-BY-NC-ND 4.0 International license. 


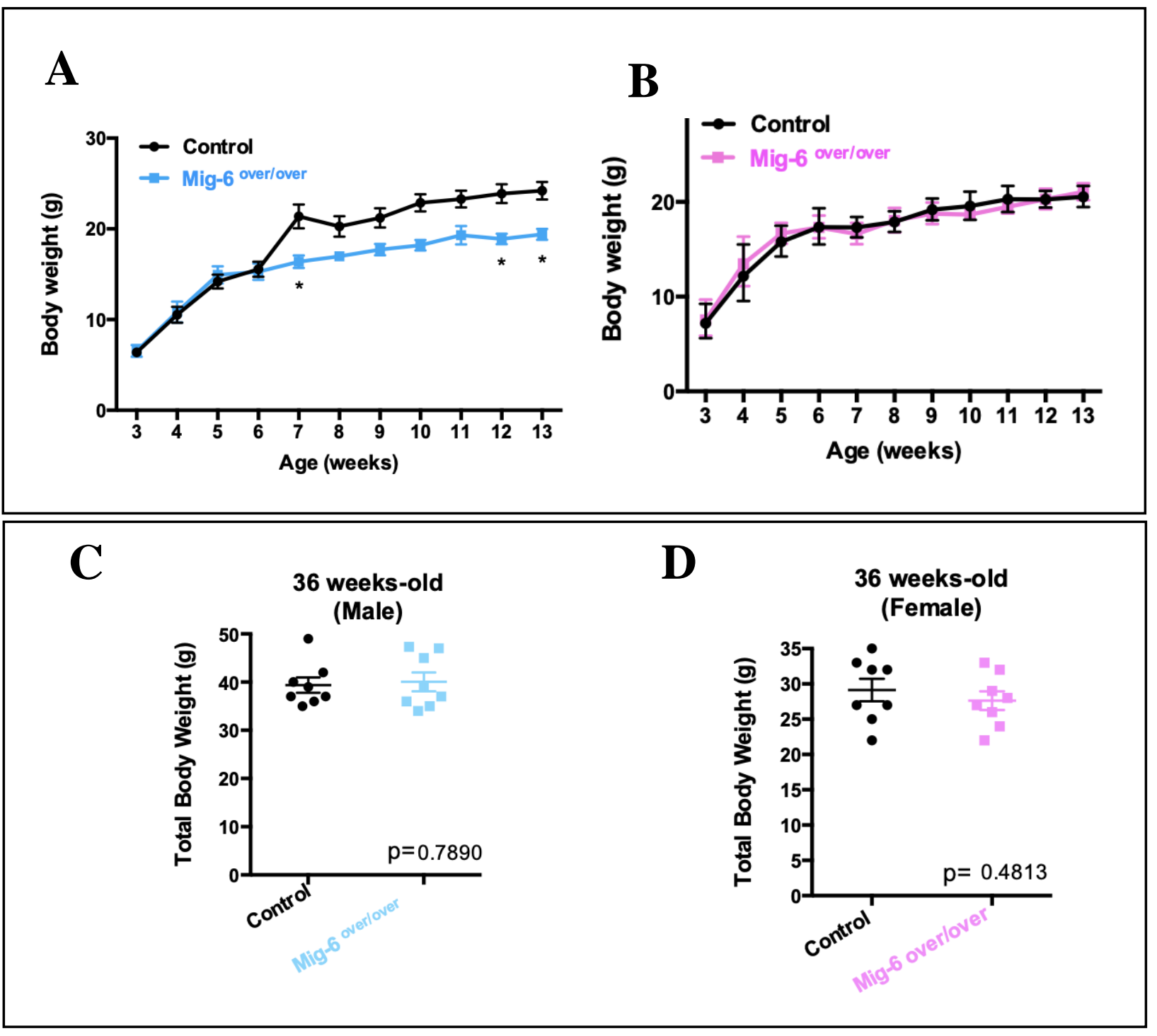

Figure 1: Total body weight of male and female control and Mig-6 ${ }^{\text {over/over }}$ mice.

Body weight of male Mig- 6 overexpressing mice did is significantly lower than control at 7w, $12 \mathrm{w}$ and $13 \mathrm{w}$ of age (A). Female Mig-6 overexpression mice did not show any statistically significant differences compared to control (B). Two-Way ANOVA was used with Bonferroni post hoc analysis ( $\mathrm{n}=5$ /genotyping). Data are presented with mean and error \pm SEM $(\mathrm{P}<0.05)$. Total body weights of 36 week-old male (C) and female (D) Mig-6 $6^{\text {over/over }}$ mice and controls did not show any statistically significant differences. Individual data points are presented with mean \pm SEM $(\mathrm{P}<0.05)$. Data were analyzed by two tailed student t-tests from 8-10 mice per group (age/genotyping). 

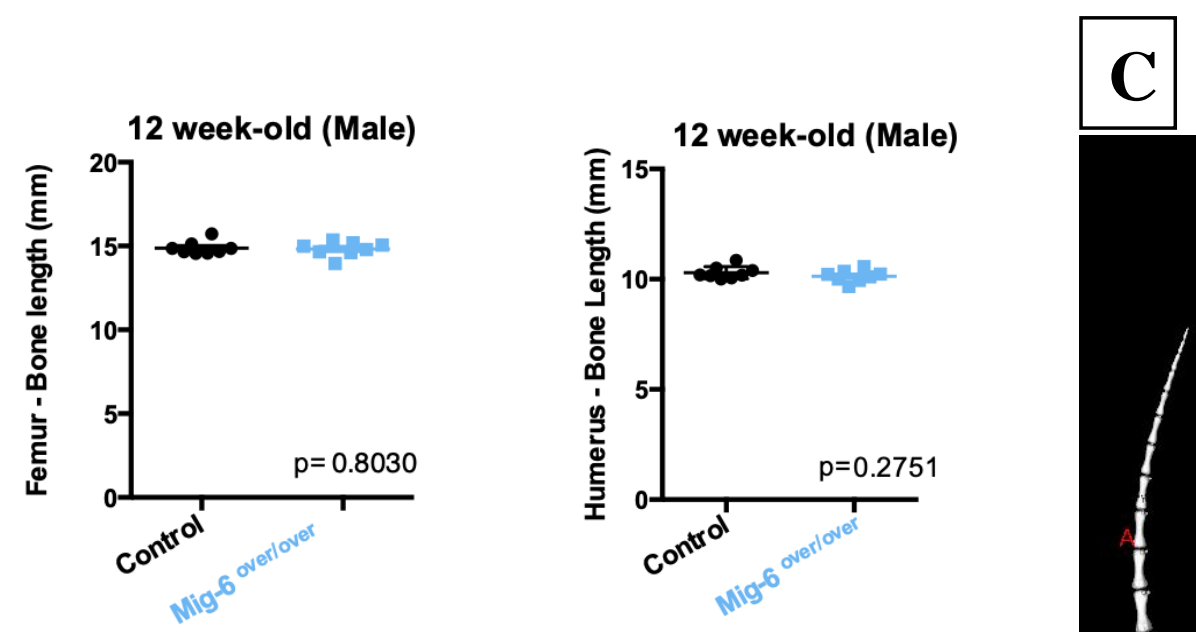

12 week-old (Male)

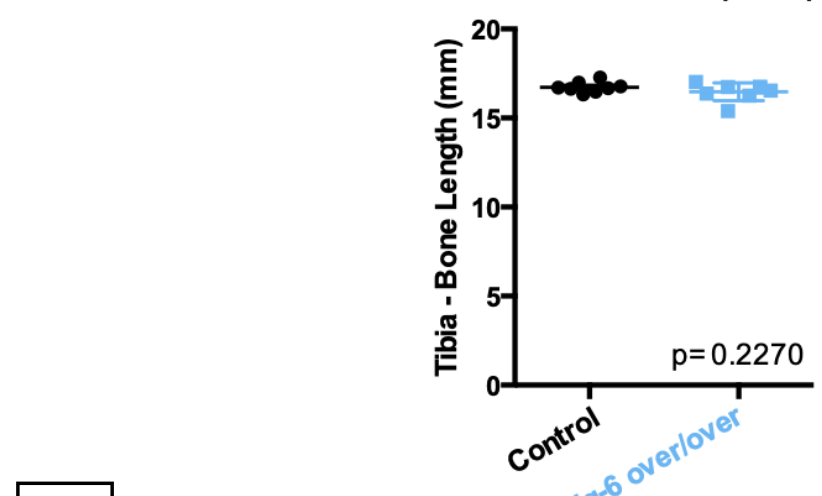

B
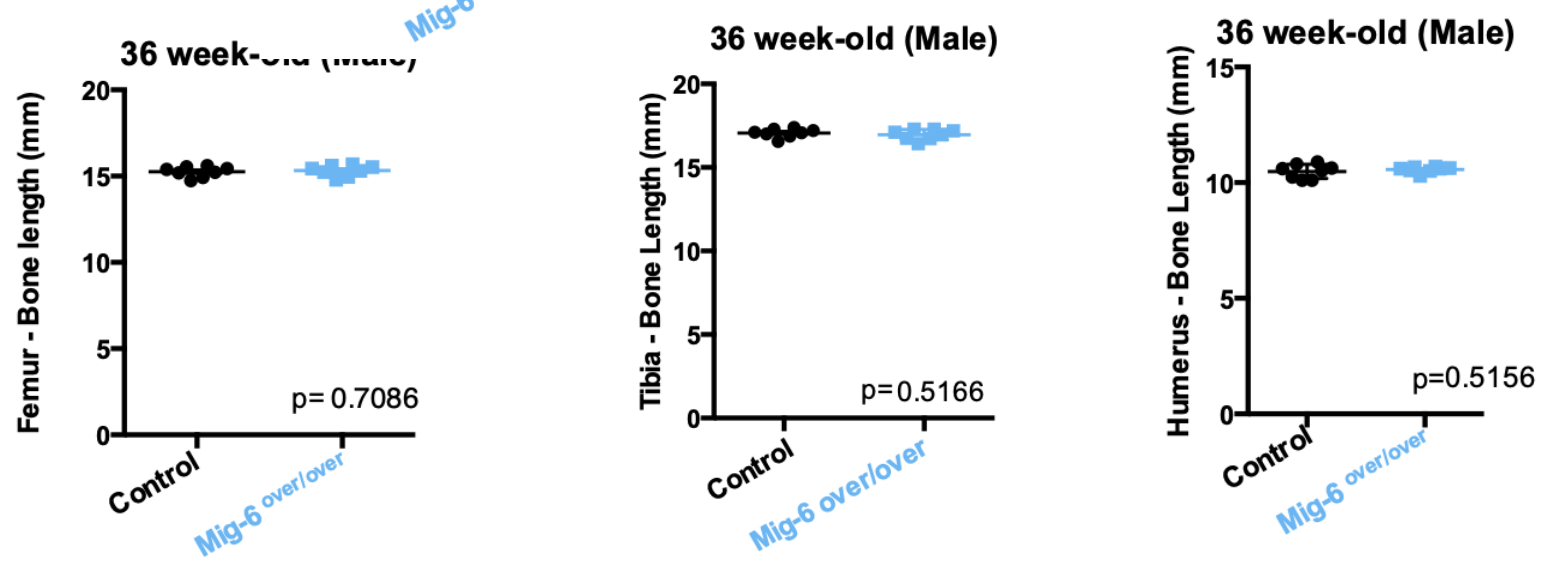

Figure 2: Mig-6 overexpression does not affect bone length.

The lengths of right femora, tibiae and humeri were measured on microCT scans of mice at 12 (A) and 36 (B) weeks of age using GE MicroView software. There were no statistically significant differences in any bones at either age. Individual data points are presented with mean \pm SEM $(\mathrm{P}<0.05)$. Data were analyzed by two tailed student $\mathrm{t}$-tests from 8 mice per group (age/gender). (C) shows a representative 3D isosurface reconstruction of a $100 \mu \mathrm{m} /$ voxel $\mu \mathrm{CT}$ scan. 

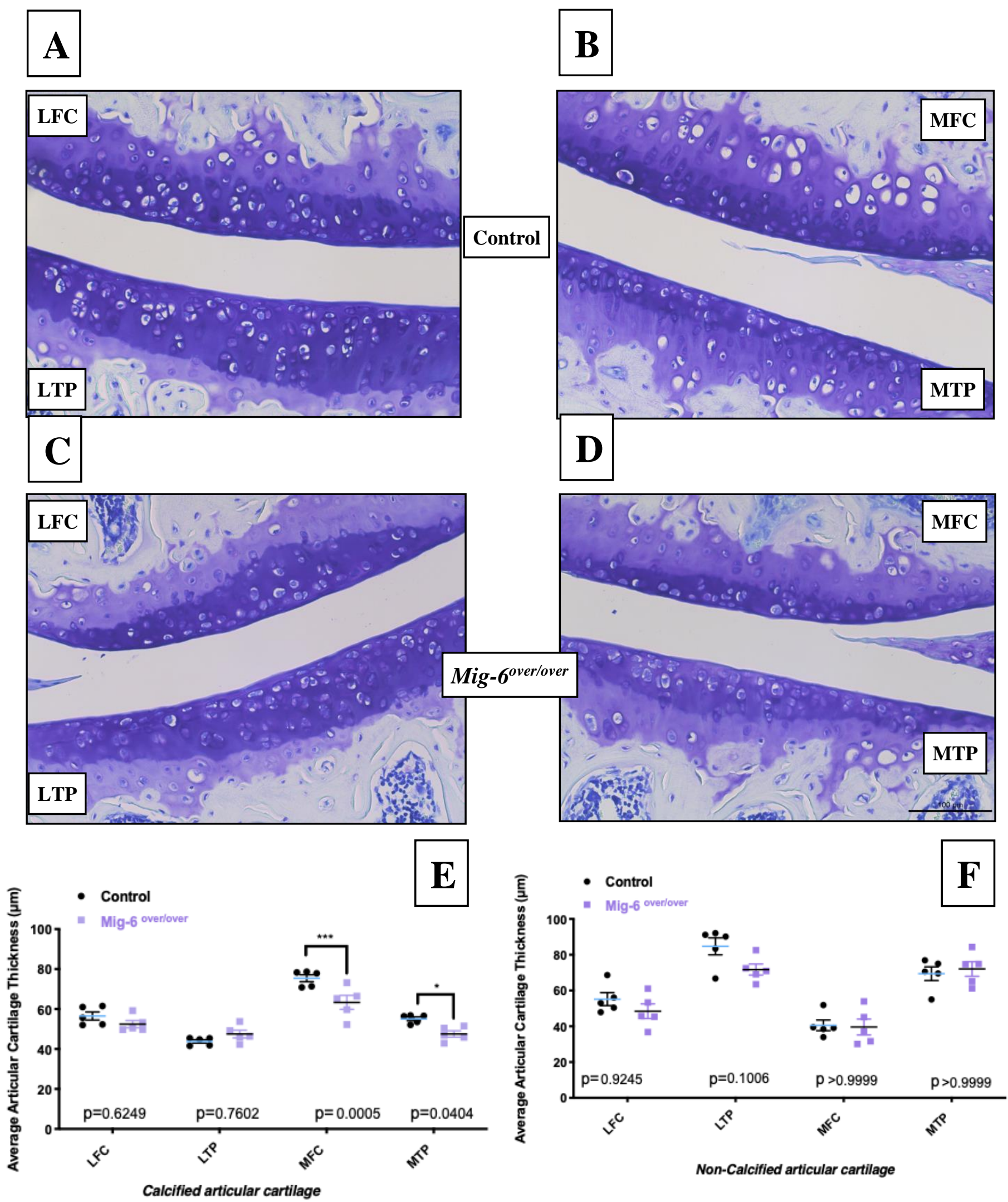


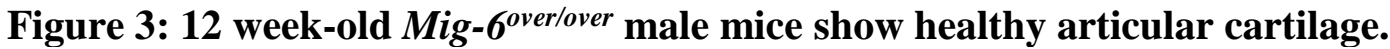

Representative $(n=5)$ toluidine blue-stained frontal sections of knee joints from 12-week-old control (A,B) and Mig-6 $6^{\text {over/over }}$ (C,D) mice showed no apparent damage. Mig-6 overexpressing mice did show statistically significant differences in thickness of the calcified articular cartilage on the medial femoral condyle (MFC) and medial tibial plateau (MTP) (E) when compared to controls. However, no statistically significant differences were seen in the non-calcified articular cartilage (F). The lateral femoral condyle (LFC) and lateral tibial plateau (LTP) did not show any significant differences. Individual data points are presented with mean \pm SEM. Data were analyzed by two-way ANOVA (95\% CI) with Bonferroni post-hoc test. Scale bar $=100 \mu \mathrm{m}$. 


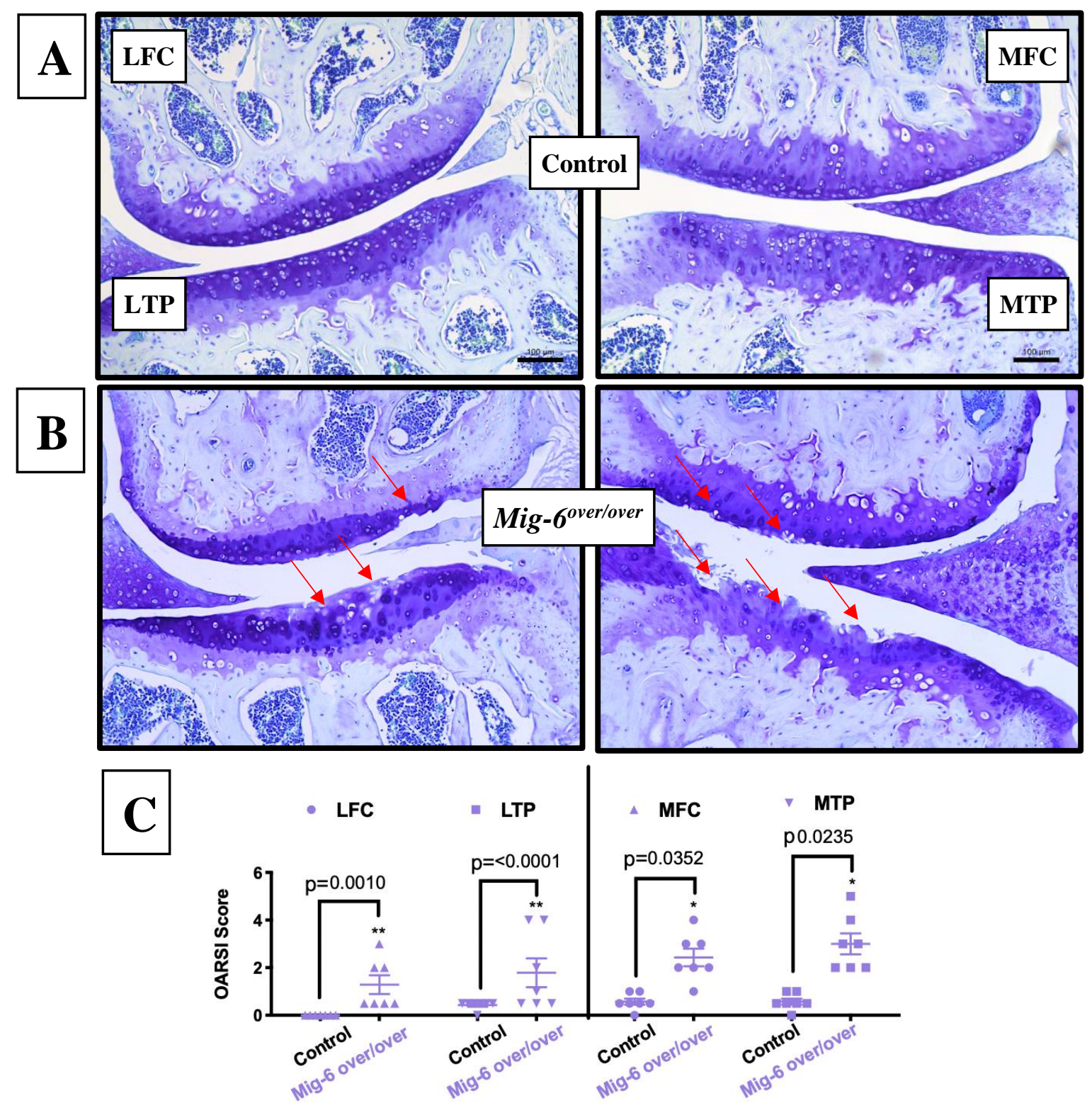

Figure 4: Cartilage damage in knee joints of 36 week-old male Mig-6 overexpressing mice. Toluidine blue staining demonstrated healthy knee joints and articular cartilage in all 36 week-old male control mice (A), while many Mig-6-overexpressing mice showed clear damage to the articular surface (B). OARSI histopathology scoring demonstrated that cartilage degeneration scores significantly increased in the MFC, MTP, LFC and LTP of Mig-6 overexpressing mice. (C) Data were analyzed by two-way ANOVA with Bonferroni's multiple comparisons test. Individual data points are presented with mean \pm SEM. All scale bars $=100 \mu \mathrm{m}$. $\mathrm{N}=7$ mice/group. 

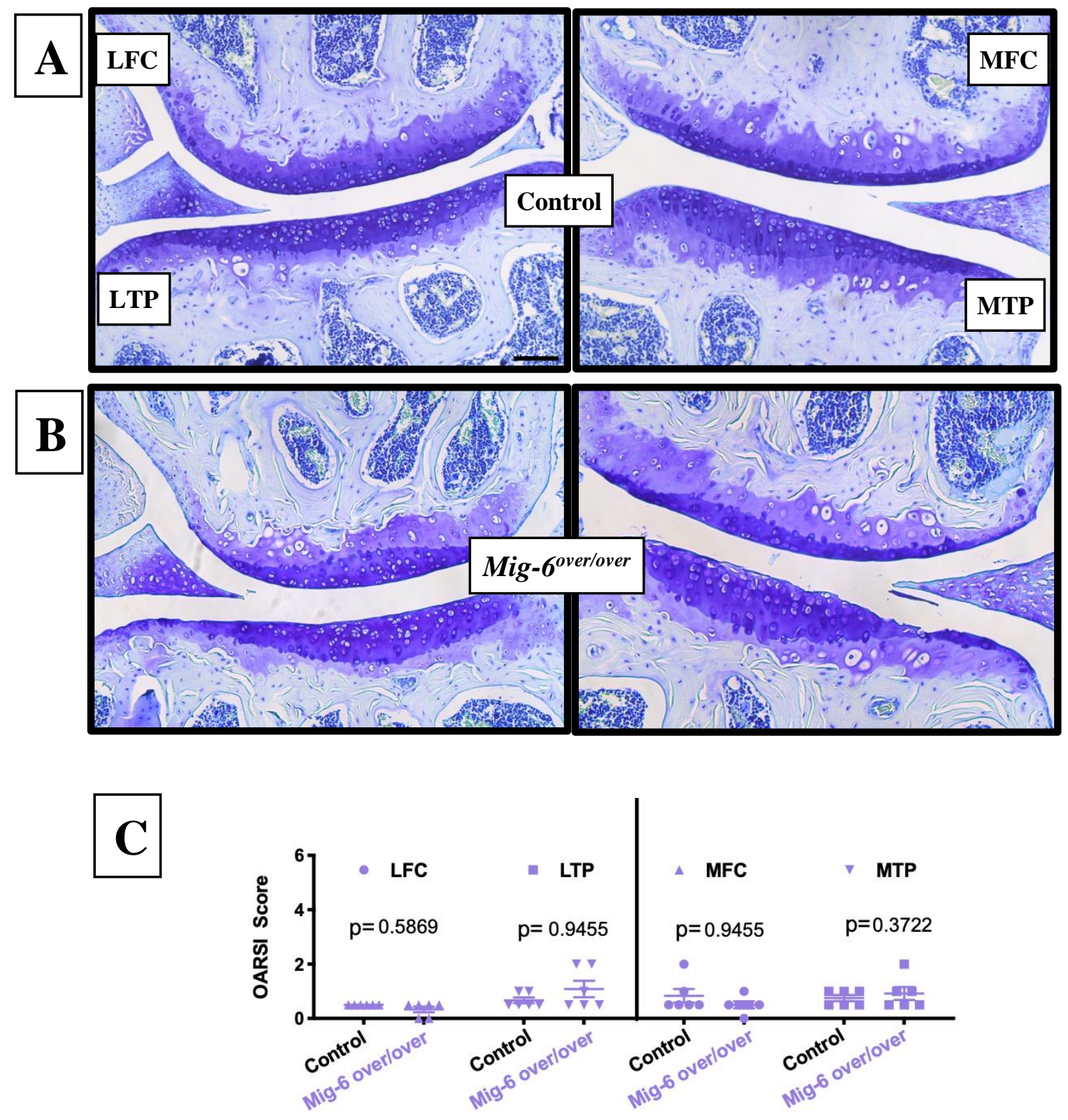

Figure 5: Minor damage in articular cartilage of 36 week-old female Mig-6 overexpressing mice. (A) Paraffin sections of knee joints from 36 week-old female control (A) and Mig-6 overexpressing (B) mice demonstrated healthy joints in controls and minor cartilage damage in some mutant mice, which was confirmed by OARSI histopathology scoring (C). Data were analyzed by two-way ANOVA with Bonferroni's multiple comparisons test. Individual data points are presented with mean \pm SEM. All scale bars $=100 \mu \mathrm{m} . \mathrm{N}=7$ mice/group. 

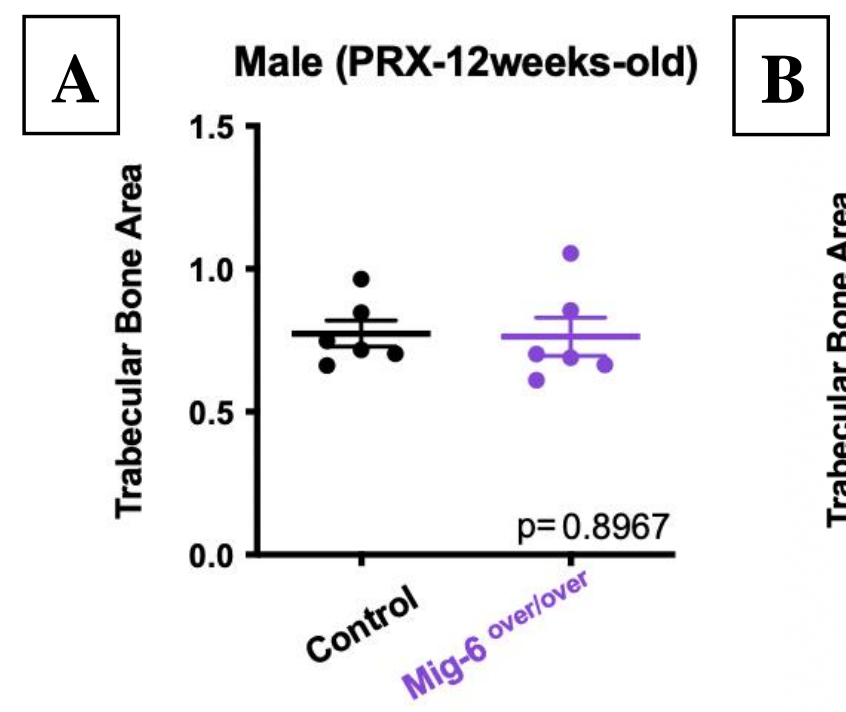

\section{Male (PRX-36weeks-old)}
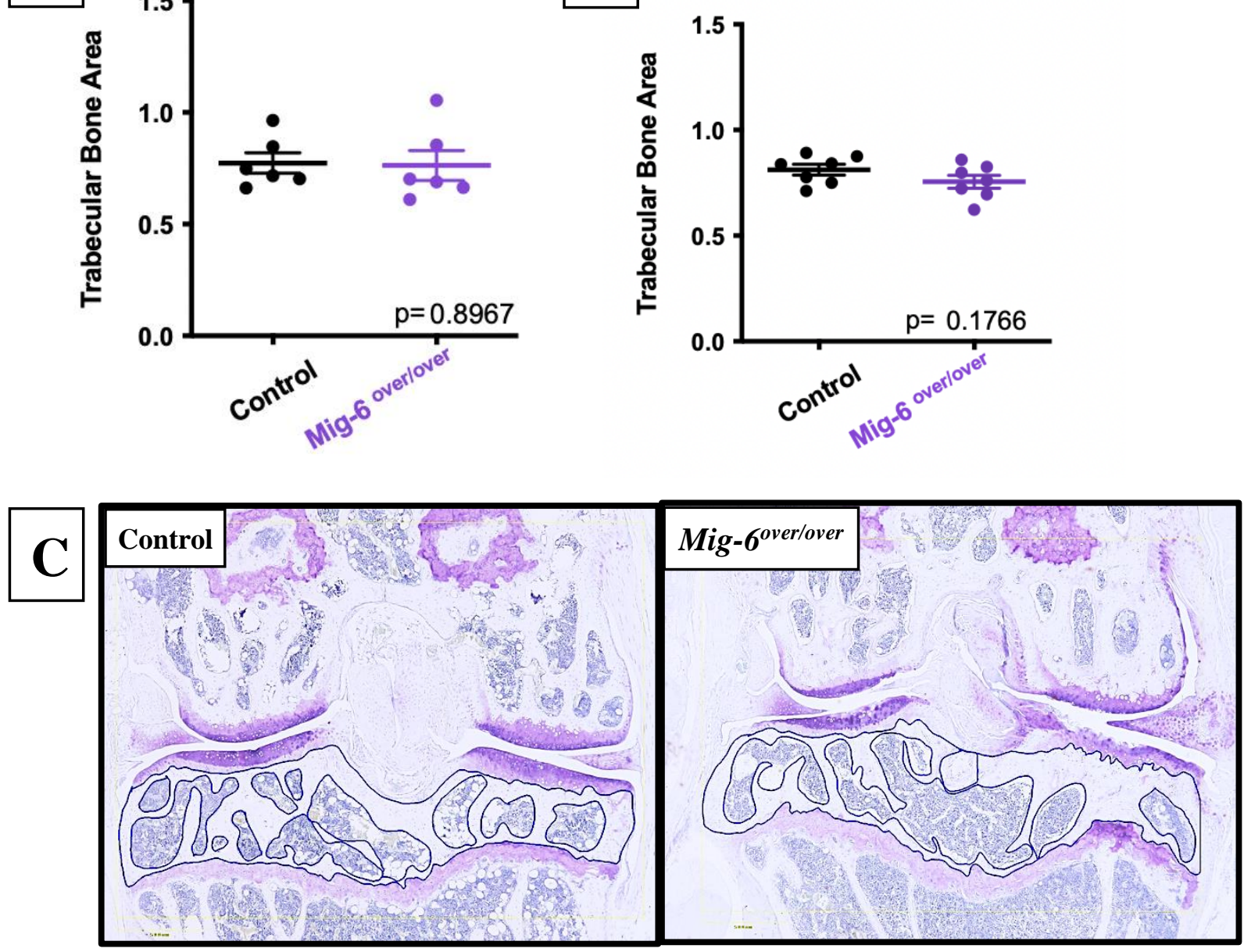

Figure 6: No differences in the subchondral bone area upon overexpression of Mig-6. The subchondral bone area from 12 week-old male control and Mig-6 overexpressing (A) or 36 week-old male control and Mig-6 overexpressing (B) mice are shown. Representative images of the subchondral area selected using the OsteoMeasure bone histomorphometry system are shown in $(\mathbf{C})$. Individual data points are presented with mean \pm SEM. Data were analyzed by one observer (MB). All scale bars $=100 \mu \mathrm{m} . \mathrm{N}=6-7$ mice/group. 

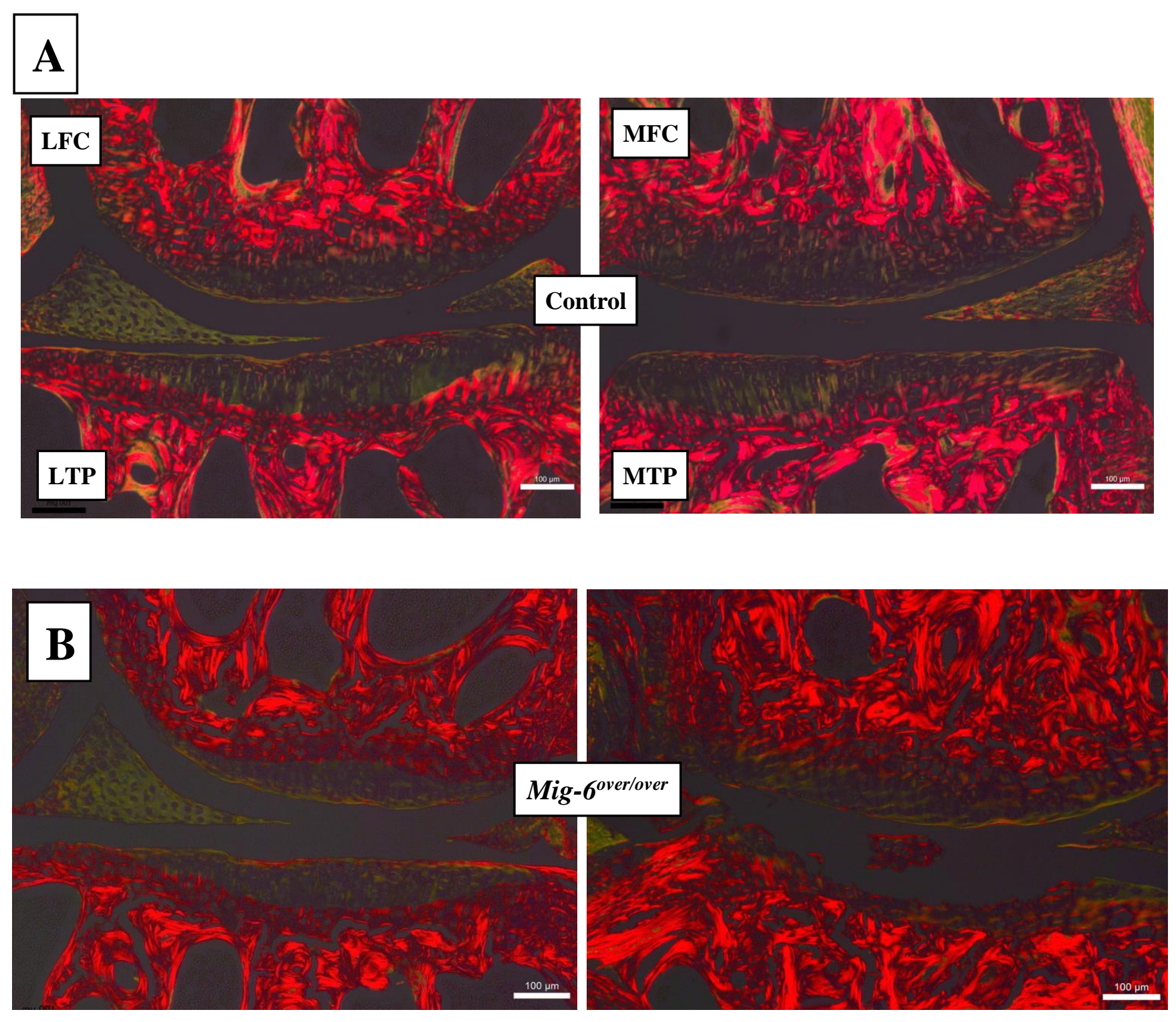

Figure 7: Picrosirius Red Staining of control and Mig-6 overexpressing mice.

Representative paraffin sections of the medial and lateral compartment in 36 week-old male control (A) and Mig-6 overexpressing mice (B) were stained with picrosirius red (fibrillar collagen) and analyzed under polarized light to evaluate the collagen tissue organization and orientation in the articular cartilage. Cartilage in the medial compartment of Mig- $6^{\text {over/over }}$ mice shows reduced collagen staining. $\mathrm{N}=5$ mice/group; $\mathrm{LFC}=$ lateral femoral condyle, LTP = lateral tibial plateau, $\mathrm{MFC}=$ medial femoral condyle and $\mathrm{MTP}=$ medial tibial plateau. Scale bar $=100 \mu \mathrm{m}$. 


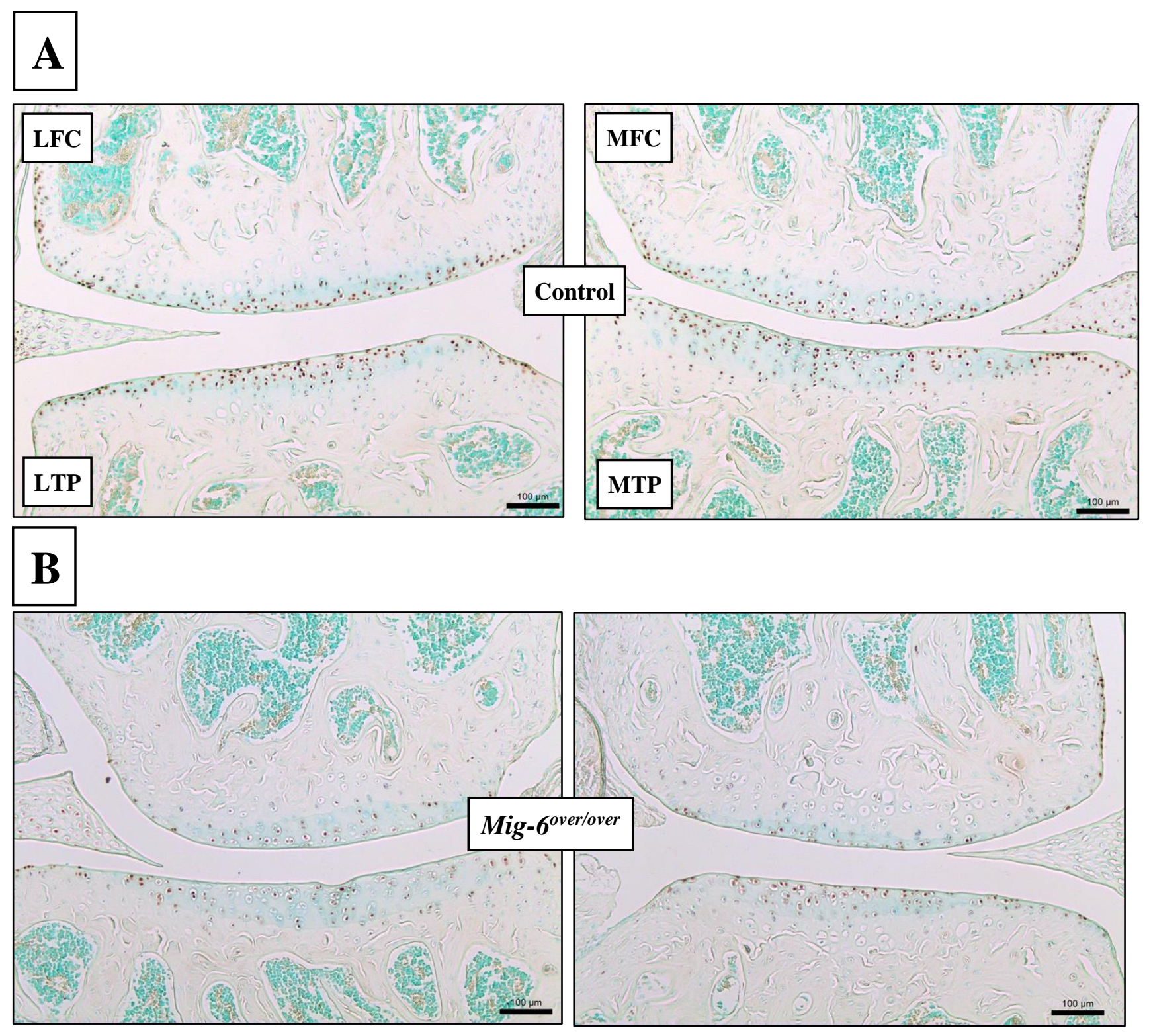

Figure 8: Lower numbers of SOX9-positive cells in 12-week old male Mig-6 overexpressing mice.

Representative SOX9 immunostaining in knee joints of 12 week-old male control (A) or Mig-6 overexpressing (B) mice ( $\mathrm{n}=5$ mice/group). Overexpressing mice showed reduced numbers of positive cells in the medial and lateral compartments. $\mathrm{LFC}=$ lateral femoral condyle, $\mathrm{LTP}=$ lateral tibial plateau, $\mathrm{MFC}=$ medial femoral condyle and MTP $=$ medial tibial plateau. Scale bar $=100 \mu \mathrm{m}$. 


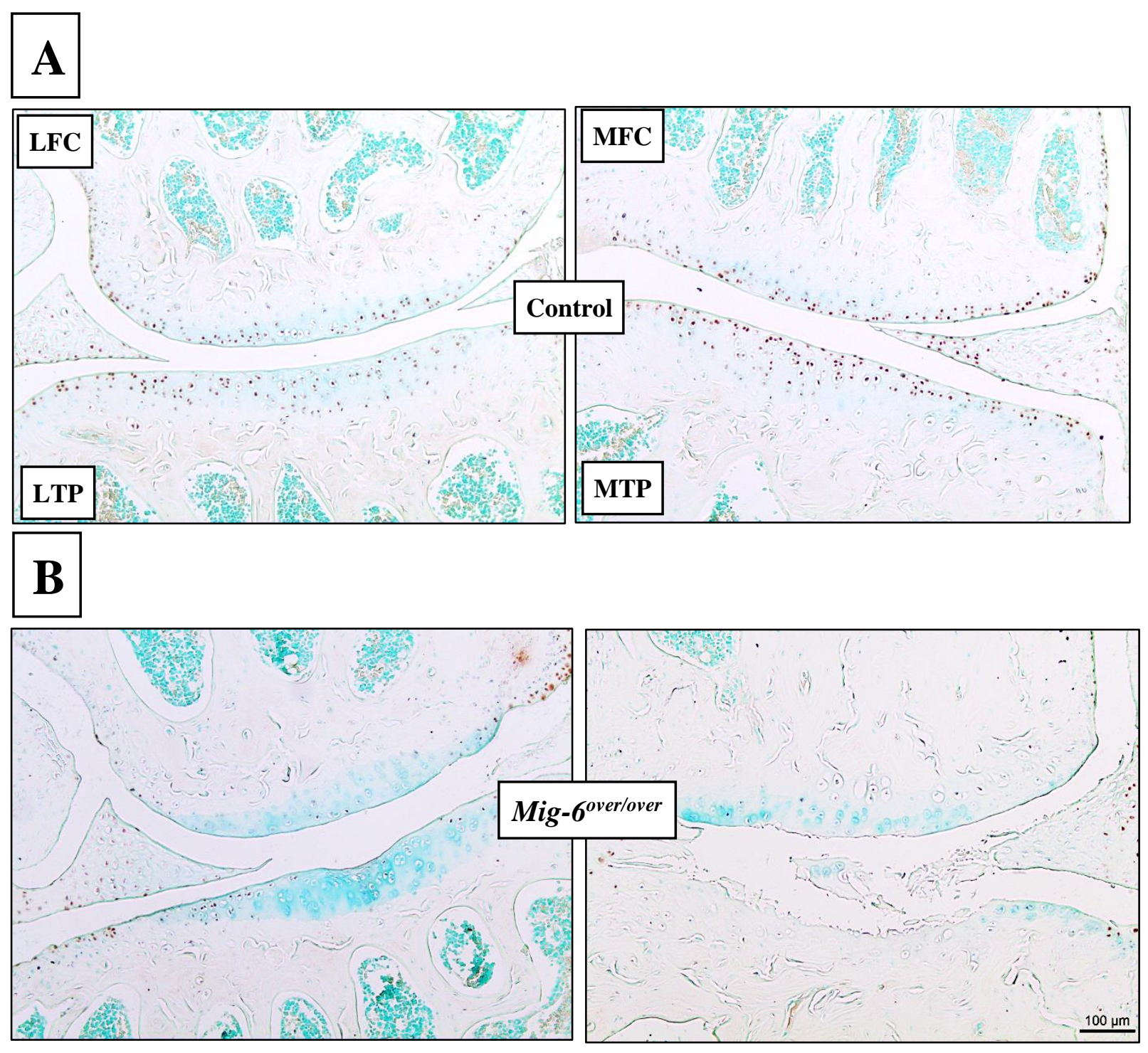

Figure 9: Lower numbers of SOX9-positive cells in 36-week old male Mig-6 overexpressing mice.

Representative SOX9 immunostaining in knee joints of 36 week-old male control (A) or Mig-6 overexpressing (B) mice ( $\mathrm{n}=5$ mice/group). Overexpressing mice showed reduced numbers of positive cells in the medial and lateral compartments. LFC = lateral femoral condyle, LTP = lateral tibial plateau, $\mathrm{MFC}=$ medial femoral condyle and MTP $=$ medial tibial plateau. Scale bar $=100 \mu \mathrm{m}$. 


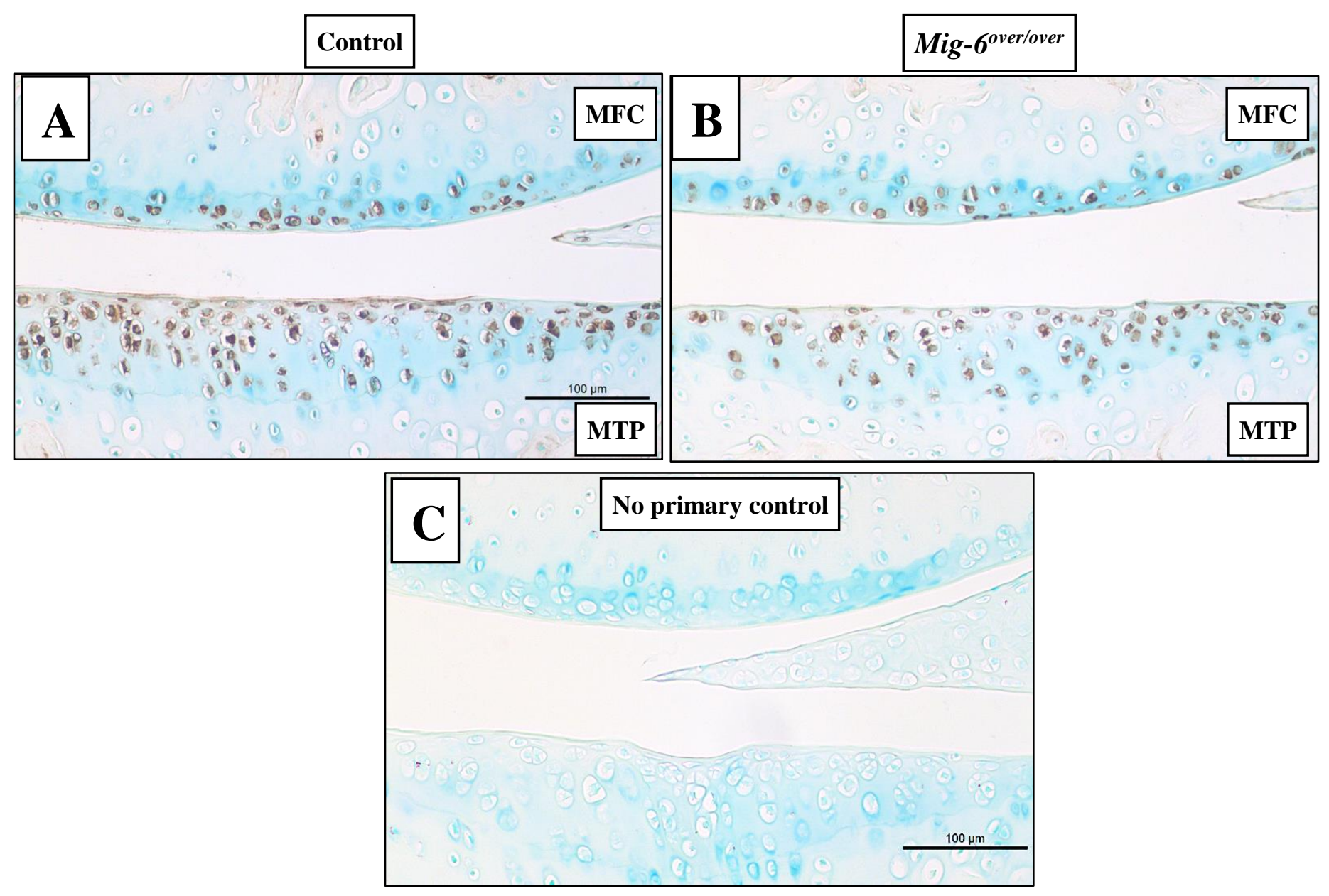

Figure 10: Lubricin immunostaining is slightly decreased in the articular cartilage of Mig-6 overexpressing mice at 12 weeks of age.

Immunostaining of sections of the knee joint indicate the presence of Lubricin (PRG4) in the superficial zone chondrocytes of 12 week-old male control mice (A), with apparently reduced staining in Mig-6 overexpressing mice (B). Frontal sections of articular cartilage with no primary antibody as negative control exhibited no staining $(\mathbf{C})$. $\mathrm{N}=5 \mathrm{mice} /$ genotyping. $\mathrm{MFC}=$ medial femoral condyle and MTP $=$ medial tibial plateau. Scale bar $=100 \mu \mathrm{m}$. 


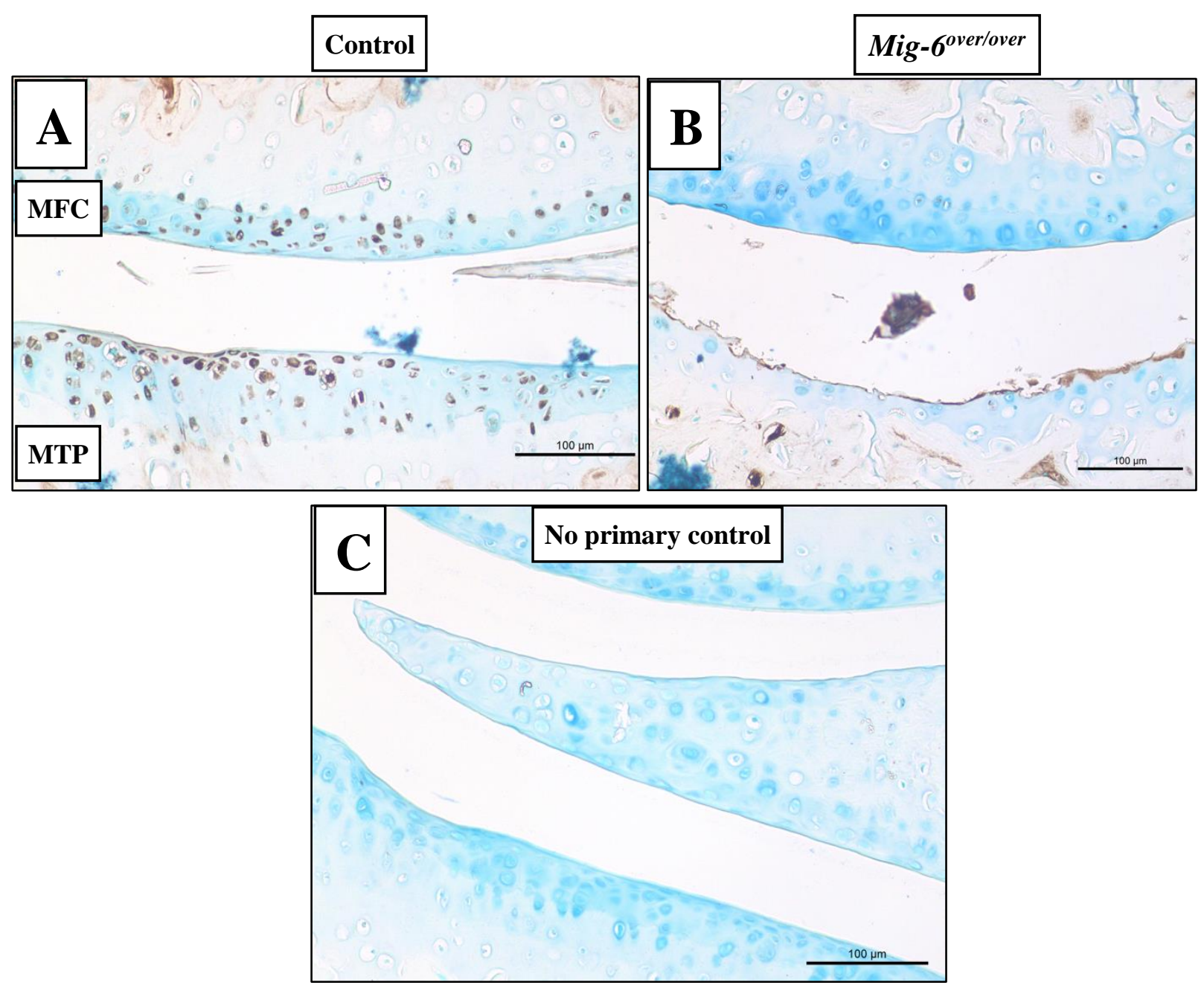

Figure 11: Lubricin immunostaining is decreased in the articular cartilage of Mig-6 overexpressing mice at 36 weeks of age.

Immunostaining of sections of the knee joints of 36 week-old male mice indicate the presence of Lubricin (PRG4) in the superficial zone of control mice (A), with markedly reduced signal in Mig6 overexpressing mice (B). Frontal sections of mice articular cartilage with no primary antibody as negative control exhibited no staining $(\mathbf{C}) . \mathrm{N}=5$ mice/genotyping. $\mathrm{MFC}=$ medial femoral condyle and MTP $=$ medial tibial plateau. Scale $b a r=100 \mu \mathrm{m}$. 

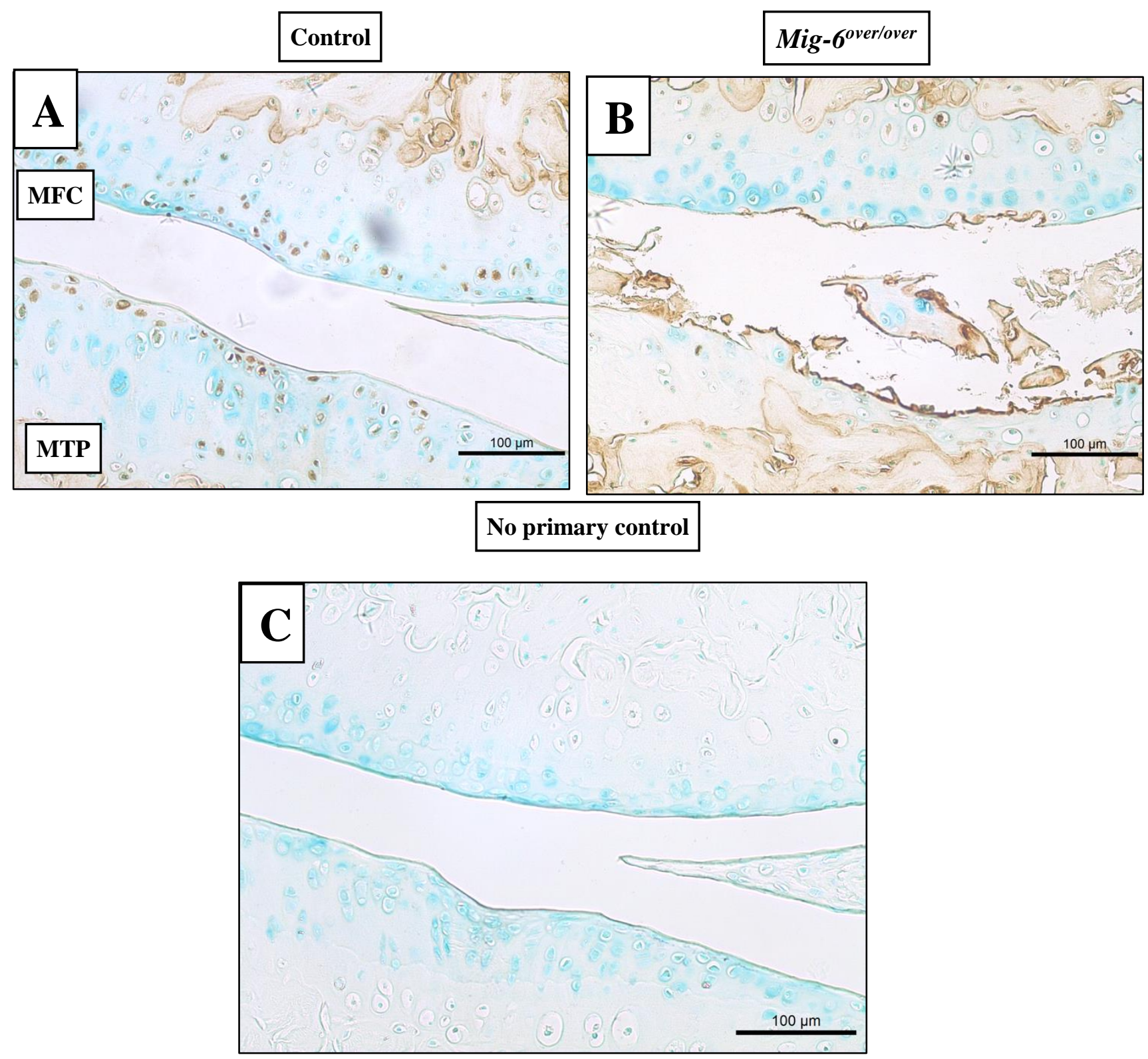

Figure 12: 36 week-old Mig-6 overexpressing mice show increased MMP13 staining in cartilage.

Representative immunohistochemistry of matrix metalloproteinase 13 ( MMP13) in 36 week-old control (A) and Mig-6 overexpressing (B) mice show increased staining in the degrading cartilage of overexpressors. No primary antibody control is shown in $(\mathbf{C}) . \mathrm{N}=5 \mathrm{mice} /$ genotyping. $\mathrm{LFC}=$ lateral femoral condyle, LTP = lateral tibial plateau, MFC = medial femoral condyle and MTP = medial tibial plateau. Scale bar $=100 \mu \mathrm{m}$. 